\title{
QUEEN'S
UNIVERSITY
BELFAST
}

\section{The effect of through-thickness compressive stress on mode II interlaminar fracture toughness}

Catalanotti, G., Furtado, C., Scalici, T., Pitarresi, G., van der Meer, F. P., \& Camanho, P. P. (2017). The effect of through-thickness compressive stress on mode II interlaminar fracture toughness. Composite Structures, 182, 153-163. https://doi.org/10.1016/j.compstruct.2017.09.014

Published in:

Composite Structures

Document Version:

Peer reviewed version

Queen's University Belfast - Research Portal:

Link to publication record in Queen's University Belfast Research Portal

Publisher rights

Copyright 2017 Elsevier.

This manuscript is distributed under a Creative Commons Attribution-NonCommercial-NoDerivs License

(https://creativecommons.org/licenses/by-nc-nd/4.0/), which permits distribution and reproduction for non-commercial purposes, provided the author and source are cited.

\section{General rights}

Copyright for the publications made accessible via the Queen's University Belfast Research Portal is retained by the author(s) and / or other copyright owners and it is a condition of accessing these publications that users recognise and abide by the legal requirements associated with these rights.

Take down policy

The Research Portal is Queen's institutional repository that provides access to Queen's research output. Every effort has been made to ensure that content in the Research Portal does not infringe any person's rights, or applicable UK laws. If you discover content in the Research Portal that you believe breaches copyright or violates any law, please contact openaccess@qub.ac.uk. 


\section{Accepted Manuscript}

The effect of through-thickness compressive stress on mode II interlaminar fracture toughness

G. Catalanotti, C. Furtado, T. Scalici, G. Pitarresi, F.P. van der Meer, P.P. Camanho

PII: S0263-8223(17)31851-2

DOI: http://dx.doi.org/10.1016/j.compstruct.2017.09.014

Reference: COST 8877

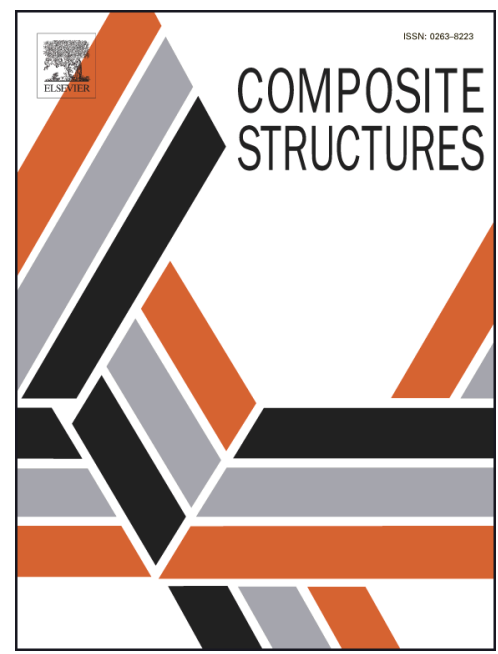

To appear in:

Composite Structures

Please cite this article as: Catalanotti, G., Furtado, C., Scalici, T., Pitarresi, G., van der Meer, F.P., Camanho, P.P., The effect of through-thickness compressive stress on mode II interlaminar fracture toughness, Composite Structures (2017), doi: http://dx.doi.org/10.1016/j.compstruct.2017.09.014

This is a PDF file of an unedited manuscript that has been accepted for publication. As a service to our customers we are providing this early version of the manuscript. The manuscript will undergo copyediting, typesetting, and review of the resulting proof before it is published in its final form. Please note that during the production process errors may be discovered which could affect the content, and all legal disclaimers that apply to the journal pertain. 


\title{
The effect of through-thickness compressive stress on mode II interlaminar fracture toughness
}

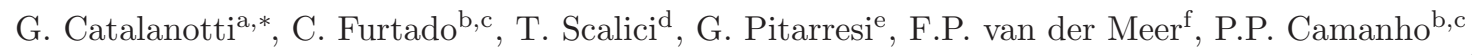 \\ ${ }^{a}$ School of Mechanical and Aerospace Engineering, Queen's University Belfast, Belfast BT9 5AH, UK \\ ${ }^{b}$ DEMec, Faculdade de Engenharia, Universidade do Porto, Rua Dr. Roberto Frias, 4200-465, Porto, Portugal. \\ ${ }^{c}$ INEGI, Rua Dr. Roberto Frias, 400, 4200-465 Porto, Portugal. \\ ${ }^{d}$ DICAM, Università degli Studi di Palermo, Viale delle Scienze, 90128 Palermo, Italy \\ e DIID, Università degli Studi di Palermo, Viale delle Scienze, 90128 Palermo, Italy \\ ${ }^{f}$ Faculty of Civil Engineering and Geosciences, Section of Structural Mechanics, Delft University of Technology, P.O. \\ Box 5048, 2600 GA Delft, The Netherlands
}

\begin{abstract}
The effect of through-thickness compressive stress on mode II interlaminar fracture toughness is investigated experimentally and replicated numerically. The modified Transverse Crack Tensile specimen recently proposed by the authors is used, together with an experimental device designed to apply a constant transverse compressive stress on the surface of the specimen. Experiments are conducted using IM7/8552 specimens for different compressive stresses, ranging from 0 to $100 \mathrm{MPa}$, covering all the practical applications commonly encountered in the aeronautical industry (e.g., tightened filled holes or bolted joints). It is shown that mode II interlaminar fracture toughness increases with the applied compressive through-thickness stress. Finally, experiments are replicated using appropriate numerical models based on cohesive elements that take into account frictional effects. A good agreement between numerical predictions and experiments is found.
\end{abstract}

Keywords: Interlaminar fracture toughness, Mode II delamination, Compressive stress

\section{Introduction}

Composite filled holes and bolted joints are well known examples of scenarios where the applied compressive stress (due to the clamping of the bolt) has a beneficial effect on the strength [1, 2, 3, ,4). The applied clamping pressure limits the propagation of the cracks that develop under the washer [4] and provides a through-thickness restraint that is reflected in an increase of the strength [3] and in a change of the failure mode [5, 6$]$.

Appropriate strength prediction methods for filled holes or bolted joints consist of Finite Elementbased numerical models based on progressive damage models [7, 8, 9, 10, 11]. The use of analytical

\footnotetext{
* Corresponding author

Email address: G.Catalanotti@qub.ac.uk (G. Catalanotti)
} 
and semi-analytical methods is limited to the case of two-dimensional stress fields [12, 13] (e.g., open holes, pinned joints) that are unable to account for the complex triaxiality of the stresses in the neighbourhood of the hole. Even though the point- or the average-stress method [14] could be still applied, the determination of the characteristic distance, $d_{c}$, would be ineffective and complicated by the fact that $d_{c}$ would now not only depend on the geometry, material and stacking sequence but also on the value of the applied clamp, washer geometry, and hole clearance.

Progressive damage models for intralaminar [7, 15, 16, 17, 10, 11, 18, 19, 20, 21, 22] and interlaminar damage [23, 24] need the definition of both physically-based failure criteria and appropriate softening laws to model the damage onset and the damage evolution, respectively. While the effect of stress triaxiality on damage onset can be taken into account using one of the numerous three-dimensional failure criteria available (e.g. [25, 26, 27]), the effect of the triaxiality on the definition of the softening law (i.e on the fracture toughness) is not yet completely understood. It is reasonable to suppose that transverse compressive stresses influence the intra- and the interlaminar values of the fracture toughness, but how? A partial answer to this question is sought in this paper for the case of mode II interlaminar fracture toughness.

There is experimental evidence [28, 29] that mode II interlaminar fracture toughness, $\mathcal{G}_{I I}^{c}$, increases with the applied compressive stress, $\sigma_{33}$. It should be pointed out that mode II interlaminar fracture toughness is one of the key parameters when modelling the onset and propagation of interlaminar cracks in bolted joints or filled hole specimens (with tightening). The presence of the bolt, in fact, constrains the reciprocal movement of the plies; if a delamination originates from the border of the hole it can only propagate at pure mode II, because the opening mode (mode I) is restrained by the presence of the bolt. Neglecting the effect of the compressive stress yields a conservative prediction of the strength and, consequently, an increase of both weight and cost.

Despite its importance, the dependence of mode II interlaminar fracture toughness on throughthickness compressive stresses was experimentally investigated in several works [28, 29, 30, 31, 32, 33, 34 .

Rhee [30] performed fracture tests in a pressurised environment between 0.1 MPa and $200 \mathrm{MPa}$. Tests were performed on carbon/epoxy unidirectional laminates and an increasing of the fracture toughness of about $25 \%$ was observed. This preliminary work was later extended to different material systems, layups, and pressure ranges [31, 32, 33, 34].

Cartié et al. [28] investigated both mode I and mode II fracture toughness using a Double Cantilever Beam (DCB) and an End Notched Flexural (ENF) specimens, respectively. Tests were conducted in a pressurised environment (up to $100 \mathrm{MPa}$ ). It was observed that while mode II interlaminar fracture toughness increased with the applied hydrostatic pressure, mode I interlaminar fracture toughness was virtually not affected. Moreover it was noted that for the material system investigated (IM7/977-2 
carbon-epoxy composite) mode II delamination fracture toughness increases up to $25 \%$ for an increase crack tips far from the region around the central transverse notch. Taking into account those results, the modified specimen is used here to measure the interlaminar fracture toughness as a function of the applied compressive stress.

[Figure 1 about here.]

The geometry of the modified TCT is perfectly suitable for the present study, where a compressive stress ( $\sigma_{33}$ in Figure 1) is superimposed to the stress field due to the load $P$ applied to the specimen. Due to symmetry, it is reasonable to expect a constant through-thickness stress (equal to $\sigma_{33}$ ) in the region of the crack tips.

Compressive stresses are applied using the device shown in Figure 2(a), designed to apply a constant 75 and uniform compressive stress, $\sigma_{33}$, during the test. 
The specimen (denoted (1) in Figure 2(b) is constrained by two lateral steel grips (denoted (2) kept together by M10 bolts (4) extending $150 \mathrm{~mm}$ across the central transverse crack. The grips are sufficiently thick $(25 \mathrm{~mm})$ and stiff to ensure that possible out of plane curvature is minimized and no spurious loads act on the specimen. The two lateral grips contain rectangular channels where the specimen is located. In each channel, two rubber inserts (3) are placed to transmit the lateral load to the specimen. Strips of CHEMFABß CF205 (i.e. a PTFE-coated glass cloth with a static friction coefficient, of $f_{s}=0.02-0.04$, according to the manufacturer) are placed between the sample and each part of the grip.

[Figure 2 about here.]

The PTFE-coated glass cloth reduces the friction on the specimens while the rubber inserts allow to uniformly distribute the normal stresses over the area of interest 1 even in presence of not perfectly aligned surfaces:2; they also allow to reduce the contact area. Reducing the contact area permits to consider the through-thickness pressure as constant (this would have been difficult to ensure if the entire surface of the specimen were in contact with the lateral grips) and reduces the torque that has to be applied to the bolts for the same value of compressive lateral stress. It is evident that, if $F_{b}$ is the axial load of a single bolt, assuming that the bolts have the same preload, the lateral pressure, $p$, is equal to:

$$
p=-\sigma_{33}=\frac{F_{b} n_{b}}{2 w l_{i}}
$$

where $n_{b}$ is the bolts number, $w$ the width of the specimen and $l_{i}$ the in plane dimension of the insert in the longitudinal direction of the specimen. It is also necessary to ensure that the load applied to the bolt remain constant during the test, compensating the loss of preload due to Poisson effects. This is done by means of disk springs (5) in Figure 2(b)], as explained in detail in Appendix A.

\section{Experiments}

\subsection{Materials and methods}

Unidirectional plates with in plane dimensions of $300 \times 300 \mathrm{~mm}^{2}$ and a thickness of $4 \mathrm{~mm}$ were manufactured with the layup, $\left[0_{8} / \tilde{0}_{16} / 0_{8}\right]$, where the tilde denotes the cut plies. After curing in a hot press according to the suppliers specification [36] the specimens were cut, using a water-cooled

\footnotetext{
${ }^{1}$ As shown in Figure 1 the pressure is applied over the region surrounding the crack tip; the inserts have a length of $20 \mathrm{~mm}$ and are placed with one edge $5 \mathrm{~mm}$ ahead of the crack tip and the other edge $15 \mathrm{~mm}$ behind the crack tip.

2 i.e. the lateral surfaces of the specimens, and the internal surfaces of the grips that go in contact with the latter ones; even if the specimen and the grips were manufactured with the standard tolerances, small misalignments may still occur.
} 
diamond blade saw, to their nominal dimensions of $15 \times 200 \mathrm{~mm}^{2}$. The relevant mechanical properties

of the unidirectional ply are shown in Table 1

[Table 1 about here.]

As explained in Section 2, the two lateral grips are mounted by means of M10 bolts. Bolt torque was applied using a DB6N Tohnichi torque wrench with a precision of $0.1 \mathrm{Nm}$ and a full scale of $6 \mathrm{Nm}$. The formula that relates the axial load, $F_{b}$, to the torque applied to the bolt, $T_{b}$, reads:

$$
F_{b}=\frac{T_{b}}{\kappa D}
$$

where $D$ is the diameter of the bolt, and $\kappa$ is the torque coefficient usually taken equal to $\kappa=0.2$ for steel bolts. Bolts instrumented with strain gauges were also used to confirm the value of $\kappa$ and therefore to ensure a correct calculation of the axial load applied to a single bolt. The signals from the strain gauges were also monitored during the test to ensure that the desired compressive stress was kept during the entire experiment.

After mounting the two lateral grips, the specimen is installed in the Instron 4208 universal testing machine, equipped with a load cell of $200 \mathrm{kN}$, as shown in Figure 3 .

[Figure 3 about here.]

A crosshead speed of $1 \mathrm{~mm} / \mathrm{min}$ was applied until unstable crack propagation occurs, identified by the first peak in the load vs. displacement curve. This load, $P_{p}$, is used in the calculation of mode II interlaminar fracture toughness. The Energy Release Rate (ERR) of the modified TCT specimens reads [35]:

$$
\mathcal{G}_{I I}=\sigma^{2} \frac{H}{2 E_{1}}\left(\frac{1}{\xi}-1\right)
$$$$
\text { ac }
$$

The results were compared to data from [35] (i.e. serie $O$ - transversely unloaded) used as control data.

\subsection{Experiments and discussion}

Table 2 shows the experimental results obtained for all the specimen tested, while Figure 4 shows the typical load-displacement curves. 
[Table 2 about here.]

It is worth noting that the load-displacement curve slightly changes when applying a high throughthickness stress (Figure 44). In particular, it is observed that for the specimen of the type A (the specimens with the lower $\sigma_{33}$ ) the load displacement curve is linear until the first peak is reached. At this point, that corresponds to the unstable crack propagation, the load displacement curve exhibits a substantial drop and the test is ended. This behaviour is also observable in specimens of type B and C. Specimens tested with an higher lateral pressure, $\sigma_{33}$, exhibit a slightly different behaviour. The load displacement curve increases, almost linearly until a point where a change in the slope of the curve is noticed (red arrow in Figure 4). The non-linearity occurs at a load that is of the same order of the peak load for the specimens that were tested with a lower lateral pressure. As showed in [35], the unstable crack propagation in the modified TCT occurs for a crack length equal to length of the fracture process zone, and this should happen also in the presence of a through-thickness pressure. In fact, the pressure, being normal to the fracture surface, should not influence the ERR that can still be calculated using Equation (3). The slight non-linearity of the load-displacement curves in Figure 4 is believed to account for the gradual formation of the fracture process zone, allowed by the modified TCT driving force curve (see [35]). It is then postulated that when lateral compressive stresses are high enough, they interfere with the creation of the process zone, e.g. by frictional effects that lead to an increase of the fracture toughness of the material. It should be observed that the first peak (i.e. the load that correspond to the unstable crack propagation) is followed by a substantial drop of the load only when the transverse pressure applied is relatively low

[Figure 4 about here.]

From the peak load, the energy release rate can be obtained substituting the peak stress, $\sigma_{p}$, in Equation (3). Figure 5 shows the fracture toughness, $\mathcal{G}_{I I}^{c}$, as a function of the through-thickness stress, $\sigma_{33}$.

[Figure 5 about here.]

As suggested by other researchers [29, 37] the dependence of the fracture toughness on throughthickness stress may be fitted with a linear law:

$$
\mathcal{G}_{I I}^{c}=\mathcal{G}_{I I 0}^{c}\left(1+\eta\left\langle-\sigma_{33}\right\rangle\right)
$$

where $\mathcal{G}_{I I 0}^{c}=1.585 \mathrm{~N} / \mathrm{mm}$ is mode II fracture toughness when no through-thickness pressure is applied, $\langle\ldots\rangle$ are the McAuley brackets, and $\eta$ is an empirical parameter. For the material system investigated the best fit was found with $\eta=0.0035 \mathrm{MPa}^{-1}$ (coefficient of determination, $R^{2}=0.65$ ). 


\section{Post-mortem analysis}

The morphology of the crack surfaces was studied by direct observation of digital macro images and through Scanning Electron Microscopy (SEM). Macro images were taken by using a digital 24 MPixels SLR camera equipped with a $40 \mathrm{~mm}$ focal length macro lens. The images were post-processed and binary images were obtained by using an ad-hoc Matlab code with a cut-off level equal to 0.22 to better highlight the actual condition of the delaminated surfaces. Scanning electron microscopy was done on the fractured surface by using a SEM Phenom World model Phenom Pro X and setting the beam accelerating voltage to $15 \mathrm{kV}$. In the case of CFRP, gold coating was not necessary to obtain a good image quality because of the electroconductivity of the carbon fibres. Figure 6 a shows a macro picture of the samples with different transverse load. To better highlight the actual condition of the samples, the binary image is presented in Figure 6 $\mathrm{b}$. From the latter, it is possible to observe a brighter area extending from the crack tips to more remote zones, becoming denser in terms of white pixels concentration as the transverse load increases.

\section{[Figure 6 about here.]}

By observing Figure 7 it is possible to highlight the differences between the brightest area and the darkest area. Figures 7(a)-left show the surface of the samples not subjected to the transverse load. As indicated by the red arrow, in this zone, there is a mix of broken fibres and hackles. This scenario changes by moving away from the crack tip (Figure 7(a)-right) where hackles dominate the surface confirming the pure mode II failure. A similar morphology is observed in a remote position of the fracture surface of the samples A (Figure 7(b)-left). On the other hand, fibres breakage is highlighted on Figure 7(b) right (red ellipses). By increasing the transverse load, fibre fracture is more evident and spreads over a larger area (Figure $7(\mathrm{c})$.

[Figure 7 about here.]

\section{Numerical modelling}

With the aim of reproducing the experiments, a Finite Element (FE) model of the specimen was implemented in Abaqus [38]. To reduce the computational effort, only one eighth of the specimen was modelled. The plies were meshed using C3D8R brick elements with a dimension of $0.5 \times 0.5 \times 0.5$ $\mathrm{mm}^{3}$, while COH3D8 finite-thickness cohesive elements were used for the interface. A thickness of $0.01 \mathrm{~mm}$ was used for the interface elements as recommended in the Abaqus Documentation [38]. The simulation was performed in two steps. In the first, a transverse pressure was applied to the specimen, trying to reproduce the effect of the lateral grips at the beginning of the test (see Figure 8(a). In the second step this pressure is maintained and a longitudinal displacement is applied to the specimen; 
this will cause (i) the reaching of damage onset in the cohesive elements (see Figure 8(b)]; (ii) the reaching of the peak load (see Figure 8(c) ; (iii) suddenly followed by an unstable crack propagation (see Figure $8(\mathrm{~d})$.

The dependence of mode II fracture properties on the transverse stress, $\sigma_{33}$ is introduced using two different approaches, and in particular: via i) a VUSDFLD (user defined field) and, ii) a VUMAT (user defined material) subroutines.

\subsection{User defined field}

185

The application of a negative transverse stress produces a change in the softening law, as shown in Figure 9, To compute the new softening law the appropriate value for the effective shear strength, $\tau_{s h}$, and fracture toughness are required.

\section{[Figure 9 about here.]}

Following Turon et al. [39] the effective shear strength, $\tau_{s h}$, is not considered a fully independent material property but instead a function of the fracture toughness for mode I and II, and the normal strength $\tau_{N}$, as:

$$
\tau_{s h}=\tau_{N}\left(\frac{\mathcal{G}_{I I}^{c}}{\mathcal{G}_{I}^{c}}\right)^{\frac{1}{2}}
$$

Substituting Equation (4) in Equation (5) yields:

$$
\tau_{s h}=\tau_{N}\left[\frac{\mathcal{G}_{I I 0}^{c}\left(1+\eta\left\langle-\sigma_{33}\right\rangle\right)}{\mathcal{G}_{I}^{c}}\right]^{\frac{1}{2}}
$$

Finally, the normal strength, $\tau_{N}$, in pure mode $\mathrm{I}$ is calculated as [40]:

$$
\bar{\tau}_{N}=\sqrt{\frac{M E \mathcal{G}_{I c}}{N_{e} l_{e}}}
$$

where $E$ is the Young's modulus, $l_{e}$ the size of the element along the direction of the crack propagation $(0.5 \mathrm{~mm}), M$ is a dimensionless parameter that depends on the adopted cohesive zone model [40, 41], and $N_{e}$ is the number of elements within the cohesive zone, that was chosen to be equal to $N_{e}=5$ [40]. Using Equation (77), the effective strength in pure mode I, $\tau_{N}$, is calculated as [40]:

$$
\tau_{N}=\min \left(\bar{\tau}_{N}, Y_{T}^{u d}\right)
$$

where $Y_{T}^{u d}$ is the transverse tensile strength for the unidirectional laminate $\left(Y_{T}^{u d}=62.3 \mathrm{MPa}\right.$ as reported in [9]). The parameters used for the delamination onset and propagation are shown in Table 3. A detailed description of these parameters and of the cohesive damage model may be found in [38, 24] and it is not reported here for the sake of conciseness. 
[Table 3 about here.]

The VUSDFLD subroutine allows the introduction of solution-dependent material properties (i.e. the effective shear strength, $\tau_{s h}$, and mode II fracture toughness, $\mathcal{G}_{I I c}$ ), as a function of a field variable, i.e. the transverse stress $\sigma_{33}$. It is worth noticing that $\tau_{s h}$ and $\mathcal{G}_{I I c}$ are computed as a function of the $\sigma_{33}$ up to failure onset. When damage occurs, $\tau_{s h}$ and $\mathcal{G}_{I I c}$ are taken as constants; to avoid the change of the cohesive law during the softening, and consequent problems in the energy regularization.

\subsection{User defined material} Sluys [4]].

The methodology proposed by Alfano and Sacco [46], briefly reported below, assumes that a Representative Elementary Area (REA) of the interface can be divided into an undamaged and a damaged part. The relative displacement $\boldsymbol{\Delta}$ experienced in both parts is equal. The interface traction can be divided into an undamaged component, $\tau^{\mathbf{u}}$, and a damaged component, $\tau^{\mathbf{d}}$. The homogenized interface traction over the REA, $\tau$, is given by:

$$
\tau=(1-d) \tau^{\mathbf{u}}+d \tau^{\mathbf{d}}
$$

where the term $(1-d) \tau^{\mathbf{u}}$ comes from the cohesive law and the term $\tau^{\mathbf{d}}$ represents friction and contact on the damaged surface. The undamaged component follows a linear elastic law:

$$
\tau^{\mathbf{u}}=\mathbf{K} \boldsymbol{\Delta}
$$

where $\mathbf{K}$ is the diagonal stiffness matrix. Following Turon et al. [49], $K_{33}=K_{n}$ and $K_{11}=K_{22}=K_{s h}$, hence the stiffness matrix reads:

$$
\mathbf{K}=\left[\begin{array}{ccc}
K_{s h} & 0 & 0 \\
0 & K_{s h} & 0 \\
0 & 0 & K_{n}
\end{array}\right]
$$

The damaged component of the interface traction is computed after division of the relative displacement into an elastic part, $\boldsymbol{\Delta}^{\mathbf{d e}}$ and an inelastic part $\boldsymbol{\Delta}^{\mathrm{di}}$. The traction in the damaged part $\tau^{\mathbf{d}}$, is related 
to $\Delta^{\text {de }}=\Delta-\Delta^{\text {di }}$ as:

$$
\tau^{\mathbf{d}}=\left[\begin{array}{ccc}
K_{s h} & 0 & 0 \\
0 & K_{s h} & 0 \\
0 & 0 & K_{n}
\end{array}\right]\left[\begin{array}{c}
\Delta_{1}-\Delta_{1}^{d i} \\
\Delta_{2}-\Delta_{2}^{d i} \\
-\left\langle-\Delta_{n}\right\rangle
\end{array}\right]
$$

The following friction function is introduced:

$$
\phi=\mu \tau_{n}^{d}+\tau_{s h}^{d}
$$

where $\mu$ is the friction coefficient, and $\tau_{s h}^{d}$ is given by:

$$
\tau_{s h}^{d}=\sqrt{\left(\tau_{1}^{d}\right)^{2}+\left(\tau_{2}^{d}\right)^{2}}
$$

The evolution of $\boldsymbol{\Delta}^{\mathrm{di}}$ is defined by the following non-associative relationship:

$$
\dot{\Delta}^{\mathbf{d i}}=\dot{\lambda}\left[\begin{array}{c}
\frac{\partial \phi}{\partial \tau_{1}^{d}} \\
\frac{\partial \phi}{\partial \tau_{2}^{d}} \\
0
\end{array}\right]=\dot{\lambda}\left[\begin{array}{c}
\frac{\tau_{1}^{d}}{\tau_{s h}^{d}} \\
\frac{\tau_{2}^{d}}{\tau_{s h}^{d}} \\
0
\end{array}\right]
$$

with the Kuhn-Tucker conditions $\dot{\lambda} \geq 0, \phi(\tau) \leq 0$ and $\dot{\lambda} \phi(\tau)=0$. Summarizing, the cohesive interface law reads:

$$
\tau=(1-d)\left[\begin{array}{ccc}
K_{s h} & 0 & 0 \\
0 & K_{s h} & 0 \\
0 & 0 & K_{n}
\end{array}\right]\left[\begin{array}{c}
\Delta_{1} \\
\Delta_{2} \\
\Delta_{n}
\end{array}\right]+d\left[\begin{array}{ccc}
K_{s h} & 0 & 0 \\
0 & K_{s h} & 0 \\
0 & 0 & K_{n}
\end{array}\right]\left[\begin{array}{c}
\Delta_{1}-\Delta_{1}^{d i} \\
\Delta_{2}-\Delta_{2}^{d i} \\
-\left\langle-\Delta_{n}\right\rangle
\end{array}\right]
$$

The cohesive interface law depends on the friction coefficient; in the following a value of $\mu=0.1$ is used.

To formulate the damage evolution law, the mixed-mode norms of the tractions, $\tau$, and the displacement jumps, $\lambda$, have to be defined (see Figure 10).

[Figure 10 about here.]

Following 24, 50] the following definition for the mixed-mode norm of the displacement jump is proposed:

$$
\lambda=\frac{K_{s h} \Delta_{s h}^{2}+K_{n} \Delta_{n}^{2}-K_{n}\left\langle-\Delta_{n}\right\rangle^{2}}{\sqrt{K_{s h}^{2} \Delta_{s h}^{2}+K_{n}^{2} \Delta_{n}^{2}-K_{n}^{2}\left\langle-\Delta_{n}\right\rangle^{2}}}
$$

The damage activation function is given by:

$$
F(\Delta)=H(\Delta)-r_{d} \leq 0
$$

where $H(\Delta)$ and $r_{d}$ are respectively a monotonic loading function and the threshold function, given by:

$$
H(\Delta)=\min \left(\frac{\lambda-\Delta^{o}}{\Delta^{f}-\Delta^{o}}, 1\right)
$$




$$
r_{d}=\max \left(1, \max _{\mathrm{s}}[H(\Delta)]\right) \quad 0<s<t \quad \forall t
$$

where $\Delta^{o}$ and $\Delta^{f}$ are the displacement jumps corresponding to delamination onset and propagation under mixed-mode conditions, respectively (see Figure 10). The Benzeggagh and Kennane criterion 51] is used to define these parameters:

$$
\begin{aligned}
& \Delta^{o}=\sqrt{\frac{K_{n}\left(\Delta_{n}^{o}\right)^{2}+\left[K_{s h}\left(\Delta_{s h}^{o}\right)^{2}-K_{n}\left(\Delta_{n}^{o}\right)^{2}\right] \beta^{\eta}}{K_{\beta}}} \\
& \Delta^{f}=\frac{K_{n} \Delta_{n}^{o} \Delta_{n}^{f}+\left[K_{s h} \Delta_{s h}^{o} \Delta_{s h}^{f}-K_{n} \Delta_{n}^{o} \Delta_{n}^{f}\right] \beta^{\eta}}{K_{\beta} \Delta^{o}}
\end{aligned}
$$

where $K_{\beta}$ is a mode-dependent interfacial stiffness defined as:

$$
K_{\beta}=K_{n}(1-\beta)+\beta K_{s h}
$$

and $\beta$ is the local mixed mode ratio defined as:

$$
\beta=\frac{K_{s h} \Delta_{s h}^{2}}{K_{s h} \Delta_{s h}^{2}+K_{n}\left\langle-\Delta_{n}\right\rangle^{2}}
$$

Finally, the damage variable is given by:

$$
d=\frac{r_{d} \Delta^{f}}{r_{d} \Delta^{f}+\left(1-r_{d}\right) r_{d} \Delta^{o}}
$$

\subsubsection{Mechanical response of the interface}

The model previously described is tested in this section using the material properties reported in Table 4. Three loading eases, corresponding to a) pure tension and pure shear, b) constant compressive stress followed by shear, and c) constant compressive stress followed by cyclic shear, are analysed in the following.

[Table 4 about here.]

a) Pure tension and pure shear are applied to the interface

The traction-displacement jump curves for pure mode I and mode II are shown in figure 11 The ${ }_{220}$ maximum strengths in mode I and mode II are respectively $\tau_{n}=40 \mathrm{MPa}$ and $\tau_{s h}=70 \mathrm{MPa}$. The dissipated energy in pure mode I and pure mode II were calculated and found to be equal to the fracture toughness in mode I, $G_{I c}$, and mode II, $G_{I I c}$, respectively.

[Figure 11 about here.] 


\subsection{Numerical results}

\section{Concluding remarks}

A modified TCT specimen recently proposed by the authors was used to measure the dependence of mode II interlaminar fracture toughness on through-thickness compressive stress. A simple and effective experimental device has been designed to apply the through-thickness stress and to avoid loss of pressure due to Poisson's effects. The main conclusions may be summarised as follows:

i) The tests conducted between 0 and $100 \mathrm{MPa}$ showed that mode II interlaminar fracture toughness increases linearly with the applied through-thickness pressure.

ii) For the IM7/8552 material system the empirical parameter that describes this linear dependence, $\eta$, is found to be equal to $\eta=0.0035 \mathrm{MPa}^{-1}$.

iii) Two different numerical approaches were implemented to take into account the pressure depen255 
account the increasing of the peak load necessary to propagate the crack in the modified TCT. The experimental results of this work will be used to validate and/or feed progressive damage models for the interlaminar crack propagation (i.e. cohesive elements formulation). It is envisaged that their use will be relevant when modelling the behaviour of bolted joints or filled holes with tightening.

\section{Appendix A: Disk washers selection}

The load of a disk spring (also known as disk washer or Belleville washer) reads [52]:

$$
F_{w}=\frac{4 E}{1-\nu^{2}} \frac{t^{4}}{K_{1} D_{e}^{2}} K_{4}^{2} \frac{s_{w}}{t}\left[K_{4}^{2}\left(\frac{h_{0}}{t}-\frac{s_{w}}{t}\right)\left(\frac{h_{0}}{t}-\frac{s_{W}}{2 t}\right)+1\right]
$$

where $D_{e}$ is outer diameter, $t$ is the thickness of the spring, $h_{0}$ is height of the cone of the disk spring without contact surfaces $\left(h_{0}=l_{0}-t, l_{0}\right.$ being the unloaded overall height of the individual disc spring), $s_{w}$ is the spring deflection, and $K_{1}$ and $K_{4}$ are two auxiliary parameters. $K_{4}$ takes the value of 1 for disc springs without contact surfaces, while $K_{1}$ reads:

$$
K_{1}=\frac{1}{\pi} \frac{\left(\frac{\delta-1}{\delta}\right)^{2}}{\frac{\delta+1}{\delta-1}-\frac{2}{\ln \delta}}
$$

with $\delta=D_{e} / D_{i}$, where $D_{i}$ is the inner diameter. The load-deflection curve of a disk spring strongly depends on the ratio of the cone height to the thickness, $h_{0} / t$, as can be seen in Equation (26). If the ratio is small ( $h_{0} / t \approx 0.4$ for the springs of $\mathrm{A}$ series in DIN $2093[53]$ ) the characteristic shape of the spring is approximately linear while for increasing ratios the spring characteristic curve becomes more and more regressive $\left(h_{0} / t \approx 0.75\right.$ and $h_{0} / t \approx 1.3$ for the springs of $\mathrm{B}$ and $\mathrm{C}$ series in DIN 2093 [53]), i.e. the load increase less than linearly with deflection. The disk springs can be stacked in parallel and/or in series allowing one to design the most appropriate load displacement curve for the correct application. In particular, the deflection of the set of spring disks, $s$, equals the deflection of the single disk multiplied by the number of the disk in series, $s=n_{s} s_{w}$, while the force of the set of springs, $F$ is equal to the force of the single disk multiplied by the number of parallel disks in the set, $F=n_{p} F_{w}$. In the present case the number of washers stacked in parallel was chosen in order to balance the load applied to the bolt, $F_{b}=n_{p} F_{w}$, for $s_{w} \approx 0.7 h_{0}$. It is worth noting that according 
to [53] the effective response of the disk washer corresponds to the theoretical curve progression, as predicted by Equation (26), only for $s_{w}<0.75 h_{0}$. For larger values of $s_{w}$ a substantial difference is observed between the theoretical and the effective curves; as a matter of fact, close to the flat position $\left(s_{w} \rightarrow h_{0}\right)$, a progressively rising force curve is observed and the characteristic curve of the spring cannot be considered regressive. The number of washers in series was chosen in order to make the characteristic curve of the set of disk springs more regressive, increasing the deflection for the same load, $F_{b}$, and consequently rendering the load less sensitive to the lateral movements of the grips. This is necessary to compensate, during the test, the contraction of the specimen, because of Poisson effects, in order not to lose the pre-load. A minimum number of four series was used for all the specimens tested; our calculations shows that in the worst conditions the load variation on a single bolt was less than $2 \%$ of the imposed pre-load. Disk springs of the $\mathrm{C}$ series were used in the experimental campaign.

\section{References}

[1] L. J. Hart-Smith. Design and Analysis of Bolted and Riveted Joints in Fibrous Composite Structures. Douglas Paper, pages 1-15, 1986. McDonnell Douglas Corporation.

[2] T. A. Collings. The Strength of Bolted Joints in Multi-Directional CFRP Laminates. Composites, $8: 43-54,1977$.

[3] F. L. Matthews, P. F. Kilty, and E. W. Godwin. Load-Carrying Joints in Fibre Reinforced Plastics. Plastic and Rubber Process and Applications, 2:19-25, 1982.

[4] G. Kretsis and F. L. Matthews. The Strength of Bolted Joints in Glass Fibre/Epoxy Laminates. Composites, 16:92-105, 1985.

[5] Y. Yan, W.-D. Wen, F.-K. Chang, and P. Shyprykevich. Experimental study on clamping effects on the tensile strength of composite plates with a bolt-filled hole. Composites Part A: Applied Science and Manufacturing, 30(10):1215 - 1229, 1999.

[6] B. Castanié, S. Crézé, J.J. Barrau, F. Lachaud, and L. Risse. Experimental analysis of failures in filled hole compression tests of carbon/epoxy laminate. Composite Structures, 92(5):1192 - 1199 , 2010.

[7] T.E. Tay, S.H.N. Tan, V.B.C. Tan, and J.H. Gosse. Damage progression by the element-failure method (EFM) and strain invariant failure theory (SIFT). Composites Science and Technology, 65(6):935-944, 2005.

[8] F. Laurin, N. Carrère, and J.-F. Maire. A multiscale progressive failure approach for composite laminates based on thermodynamical viscoelastic and damage models. Composites Part A: Applied Science and Manufacturing, 38(1):198-209, 2007. 
[9] P.P. Camanho, P. Maimí, and C.G. Dávila. Prediction of size effects in notched laminates using continuum damage mechanics. Composites Science and Technology, 67(13):2715-2727, 2007.

[10] M.R. Wisnom. Modelling discrete failures in composites with interface elements. Composites Part A: Applied Science and Manufacturing, 41(7):795-805, 2010.

[11] F.P. van der Meer, C. Oliver, and L.J. Sluys. Computational analysis of progressive failure in a notched laminate including shear nonlinearity and fiber failure. Composites Science and Technology, 70(4):692-700, 2010.

[12] P.P. Camanho, G.H. Erçin, G. Catalanotti, S. Mahdi, and P. Linde. A finite fracture mechanics model for the prediction of the open-hole strength of composite laminates . Composites Part A: Applied Science and Manufacturing, 43(8):1219 - 1225, 2012.

[13] G. Catalanotti and P.P. Camanho. A semi-analytical method to predict net-tension failure of mechanically fastened joints in composite laminates . Composites Science and Technology, 76:69 $-76,2013$.

[14] J.M. Whitney and R.J. Nuismer. Stress Fracture Criteria for Laminated Composites Containing Stress Concentrations. Journal of Composite Materials, 8(3):253-265, 1974.

[15] C. Schuecker and H.E. Pettermann. A continuum damage model for fiber reinforced laminates based on ply failure mechanisms. Composite Structures, 76(1-2):162-173, 2006.

[16] P. Maimí, P.P. Camanho, J.A. Mayugo, and C.G. Dávila. A continuum damage model for composite laminates: Part I - Constitutive model. Mechanics of Materials, 39(10):897-908, 2007.

[17] P. Maimí, P.P. Camanho, J.A. Mayugo, and C.G. Dávila. A continuum damage model for composite laminates: Part II - Computational implementation and validation. Mechanics of Materials, 39(10):909-919, 2007.

[18] E. Abisset, F. Daghia, and P. Ladevze. On the validation of a damage mesomodel for laminated composites by means of open-hole tensile tests on quasi-isotropic laminates. Composites Part A: Applied Science and Manufacturing, 42(10):1515-1524, 2011.

[19] E.V. Iarve, M.R. Gurvich, D.H. Mollenhauer, C.A. Rose, and C.G. Dávila. Mesh-independent matrix eracking and delamination modeling in laminated composites. International Journal for Numerical Methods in Engineering, 88(8):749-773, 2011.

[20] B.G. Falzon and P. Apruzzese. Numerical analysis of intralaminar failure mechanisms in composite structures. Part I: FE implementation . Composite Structures, 93(2):1039 - 1046, 2011.

[21] B.G. Falzon and P. Apruzzese. Numerical analysis of intralaminar failure mechanisms in composite structures. Part II: Applications . Composite Structures, 93(2):1047 - 1053, 2011.

[22] P.P. Camanho, M.A. Bessa, G. Catalanotti, M. Vogler, and R. Rolfes. Modeling the inelastic deformation and fracture of polymer composites - Part II: Smeared crack model. Mechanics of Materials, 59:36 - 49, 2013. 
[23] Y. Qiu, M.A. Crisfield, and G. Alfano. An interface element formulation for the simulation of delamination with buckling. Engineering Fracture Mechanics, 68(16):1755-1776, 2001.

[24] A. Turon, P.P. Camanho, J. Costa, and C.G. Dávila. A damage model for the simulation of delamination in advanced composites under variable-mode loading. Mechanics of Materials, 38(11):1072 $1089,2006$.

[25] A. Puck and H. Schürmann. Failure analysis of FRP laminates by means of physically based phenomenological models. Composites Science and Technology, 62(12-13 SPECIAL ISSUE):1633$1662,2002$.

[26] G. Catalanotti, P.P. Camanho, and A.T. Marques. Three-dimensional failure criteria for fiberreinforced laminates. Composite Structures, 95:63-79, 2013.

[27] P.P. Camanho, A. Arteiro, A.R. Melro, G. Catalanotti, and M. Vogler. Three-dimensional invariant-based failure criteria for fibre-reinforced composites. International Journal of Solids and Structures, 55:92 - 107, 2015.

[28] D. Cartié, P. Davies, M. Peleau, and I.K. Partridge. The influence of hydrostatic pressure on the interlaminar fracture toughness of carbon/epoxy composites. Composites Part B: Engineering, $37: 292-300,2006$.

[29] Q. Bing and C. T. Sun. Effect of compressive transverse normal stress on mode II fracture toughness in polymeric composites. International Journal of Fracture, 145(2):89-97, 2007.

[30] K.Y. Rhee. Hydrostatic pressure effect on the fracture toughness of unidirectional (0-deg) graphite/epoxy laminated composites. Journal of Composite Materials, 34(7):599-613, 2000.

[31] K.Y. Rhee, H.S. Oh, S.H. Jang, and S.-J. Park. Delamination characteristics of multi-directional carbon fiber/epoxy composites under high pressure. Polymer Composites, 22(6):793-802, 2001.

[32] K.Y. Rhee, S.J. Park, and J.H. Lee. On the application of $\eta$-factor approach to determine compressive fracture toughness of fiber-reinforced composites under hydrostatic pressure environment. Composites Science and Technology, 63(6):829-837, 2003.

[33] K.Y. Rhee, S.G. Lee, and J.H. Lee. Effect of hydrostatic pressure on the elastic work factor, $\eta_{e l}$ and fractures toughness determination of unidirectional composites using $\eta_{e l}$. Materials Science and Engineering A, 349(1-2):218-223, 2003.

[34] K.Y. Rhee, C.H. Chi, and S.J. Park. Experimental investigation on the compressive characteristics of multi-directional graphite/epoxy composites under hydrostatic pressure environment. Materials Science and Engineering A, 360(1-2):1-6, 2003.

[35] T. Scalici, G. Pitarresi, G. Catalanotti, F.P. van der Meer, and A. Valenza. The Transverse Crack Tension test revisited: An experimental and numerical study. Composite Structures, 158:144$159,2016$.

[36] Catalanotti G, Xavier J, and Camanho PP. Measurement of the compressive crack resistance curve 
of composites using the size effect law. Composites Part A: Applied Science and Manufacturing, $56: 300-307,2014$.

[37] Xiangqian Li, Stephen R. Hallett, and Michael R. Wisnom. Predicting the effect of throughthickness compressive stress on delamination using interface elements. Composites Part A: Applied interface elements. Journal of Composite Materials, 32(14):1246-1272, 1998.

[48] F. P. van der Meer and L. J. Sluys. A numerical investigation into the size effect in the transverse crack tensile test for mode II delamination. Composites Part A: Applied Science and Manufacturing, 54:145-152, 2013.

[49] A. Turon, E. V. González, Sarrado C., G. Guillamet, and Maimí. Accurate simulation of delamination under mixed-mode loading using a cohesive model with a mode-dependent penalty stiffness. Composite Structures, 2017. Under review. 
[55] Camanho PP, Tavares CML, Almeida JB, Bandeira PM, Portela PM, Melro A, de Oliveira R, and Figueiredo M. Inserts for CFRP Structures - Technical note 4. Technical report, European Space Agency (ESA), 2005. 
Table 1: Properties of the cured Hexcel IM7-8552 unidirectional lamina

\begin{tabular}{lr}
\hline \hline$E_{1}[\mathrm{MPa}]$ & 171420 \\
$E_{2}[\mathrm{MPa}]$ & 9080 \\
$G_{12}[\mathrm{MPa}]$ & 5290 \\
$\nu_{12}[-]$ & 0.32 \\
\hline \hline
\end{tabular}

Table 2: Test matrix and experimental results

\begin{tabular}{|c|c|c|c|c|c|c|}
\hline $\begin{array}{l}\text { specimen } \\
\text { label }\end{array}$ & $\begin{array}{c}\sigma_{33} \\
{[\mathrm{MPa}]}\end{array}$ & $\begin{array}{c}\sigma_{p} \\
{[\mathrm{MPa}]}\end{array}$ & $\begin{array}{c}\mathcal{G}_{I I}^{c} \\
{[\mathrm{~N} / \mathrm{mm}]}\end{array}$ & $\begin{array}{c}\operatorname{Ave}\left(\mathcal{G}_{I I}^{c}\right) \\
{[\mathrm{N} / \mathrm{mm}]}\end{array}$ & $\begin{array}{c}\operatorname{STDV}\left(\mathcal{G}_{I I}^{c}\right) \\
{[\mathrm{N} / \mathrm{mm}]}\end{array}$ & $\begin{array}{r}\mathrm{CI}_{95 \%}\left(\mathcal{G}_{I I}^{c}\right) \\
{[\mathrm{N} / \mathrm{mm}]}\end{array}$ \\
\hline $\mathrm{O}_{1}^{\dagger}$ & & 517 & 1.56 & & & \\
\hline $\mathrm{O} 2^{\dagger}$ & 0 & 498 & 1.45 & 150 & ( 17 & \\
\hline $\mathrm{O} 3^{\dagger}$ & U & 538 & 1.69 & 1.59 & 0.11 & 0.1 \\
\hline $\mathrm{O} 4^{\dagger}$ & & 535 & 1.67 & & & \\
\hline A1 & & 555 & 1.80 & & & \\
\hline A2 & -17 & 531 & 1.64 & 1.63 & 0.17 & 0.41 \\
\hline A3 & & 500 & 1.46 & & & \\
\hline B1 & & 550 & 1.76 & & & \\
\hline B2 & -34 & 590 & 2.03 & 1.93 & 0.14 & 0.35 \\
\hline B3 & & 583 & 1.98 & & & \\
\hline C1 & & 555 & 1.80 & 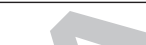 & & \\
\hline $\mathrm{C} 2$ & -51 & 599 & 2.09 & 1.99 & 0.17 & 0.41 \\
\hline C3 & & 597 & 2.08 & & & \\
\hline E1 & & 568 & 1.89 & $\gamma$ & & \\
\hline E2 & -85 & 599 & 2.09 & 2.00 & 0.10 & 0.26 \\
\hline E3 & & 587 & 2.01 & & & \\
\hline F1 & & 605 & 2.14 & & & \\
\hline $\mathrm{F} 2$ & -102 & 612 & 2.18 & 2.13 & 0.06 & 0.15 \\
\hline F3 & & 594 & 2.06 & & & \\
\hline
\end{tabular}

$\dagger$ Data reported in [35]

$\ddagger$ Confidence Interval at $95 \%$

Table 3: Interlaminar material properties

\begin{tabular}{llcr}
\hline \hline & Material property & Value or calculation method & Ref. \\
\hline$K\left[\mathrm{~N} / \mathrm{mm}^{3}\right]$ & Penalty stiffness & $10^{6}$ & {$[54]$} \\
$\tau_{N}[\mathrm{MPa}]$ & Effective strength in pure mode I & Eq. $[(8)$ & {$[40]$} \\
$\tau_{s h}[\mathrm{MPa}]$ & Effective strength in pure mode II & Eq. & {$[6]$} \\
$\mathcal{G}_{I c}[\mathrm{~N} / \mathrm{mm}]$ & Mode I fracture toughness & 0.28 & {$[39]$} \\
$\mathcal{G}_{I I c 0}[\mathrm{~N} / \mathrm{mm}]$ & Mode II fracture toughness when $\sigma_{33}=0$ & 1.59 & {$[55]$} \\
\hline \hline
\end{tabular}


Table 4: Material properties of the interface

\begin{tabular}{ccccccc}
\hline \hline $\mathcal{G}_{I c}[\mathrm{~N} / \mathrm{mm}]$ & $\mathcal{G}_{I I c}[\mathrm{~N} / \mathrm{mm}]$ & $\tau_{n}[\mathrm{MPa}]$ & $\tau_{s h}[\mathrm{MPa}]$ & $K\left[\mathrm{~N} / \mathrm{mm}^{3}\right]$ & $\eta[-]$ & $\mu[-]$ \\
\hline 0.75 & 1.5 & 40 & 70 & $1 \times 10^{6}$ & 1.45 & 0.2 \\
\hline \hline
\end{tabular}




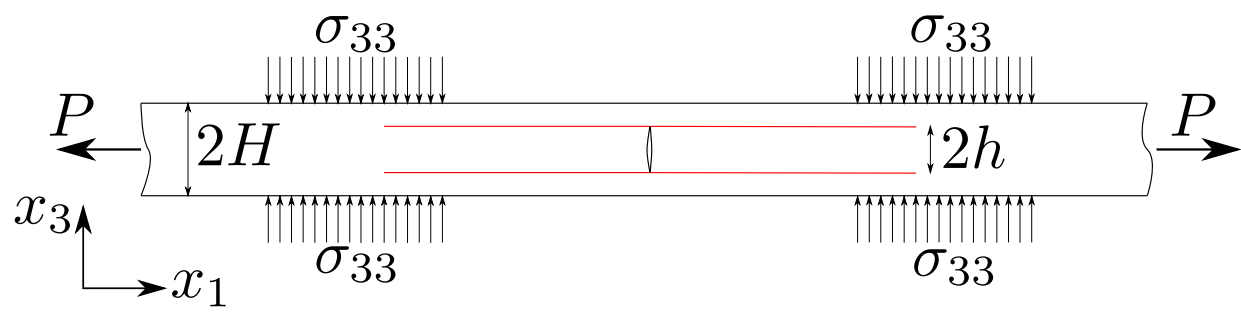

Figure 1: Specimen: geometry, coordinate system and loading.

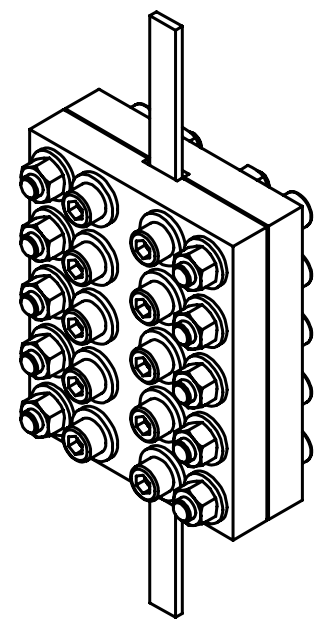

(a) Assembly.

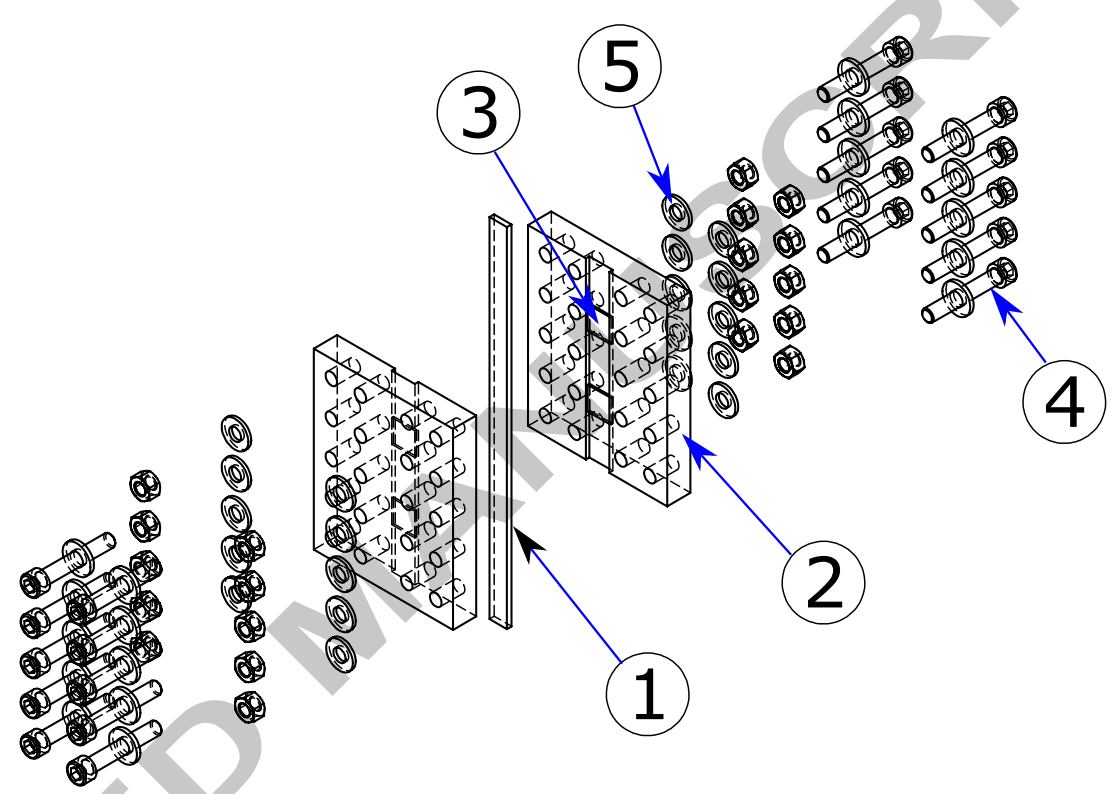

(b) Exploded view: (1) specimen, (2) lateral grips, (3) teflon inserts, (4) M10 bolts, (5) disk washers

Figure 2: Technical drawing.

b) The interface is subjected to constant compressive stress followed by shear displacement

The traction-displacement jump curves for different applied compressive stresses are shown in Figure 12. The mechanical response is characterized by three distinct regions:

(i) Firstly, the interface presents a linear elastic behaviour until a stress higher that the $\tau_{s h}$ is reached;

(ii) Secondly, the stress continues to increase non-linearly until a maximum strength is reached; 


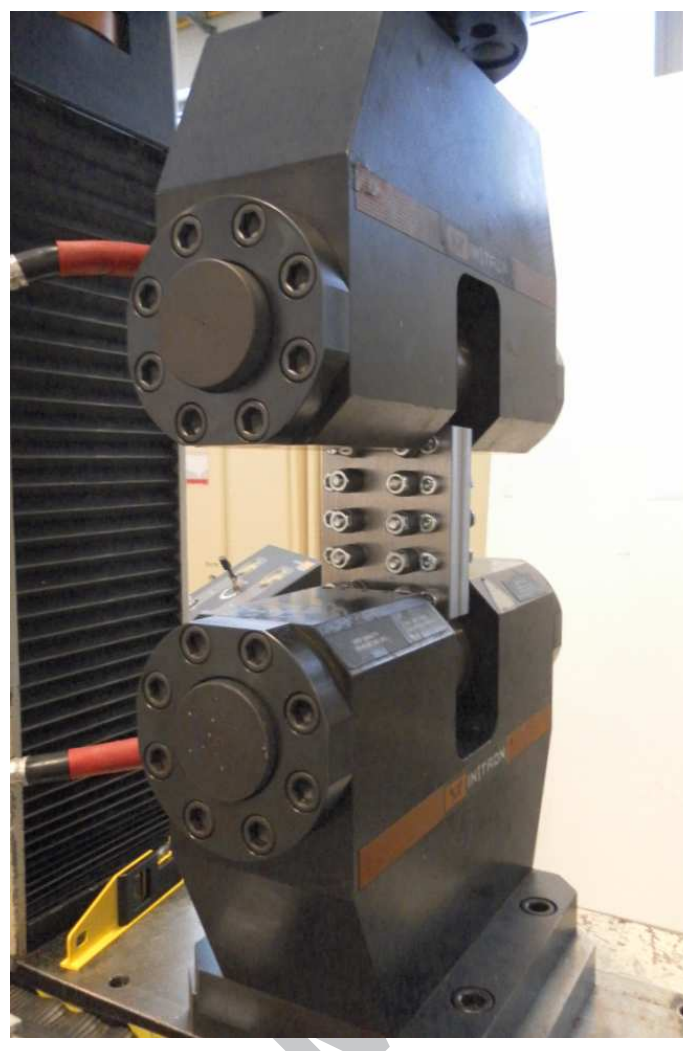

Figure 3: Experimental set-up.

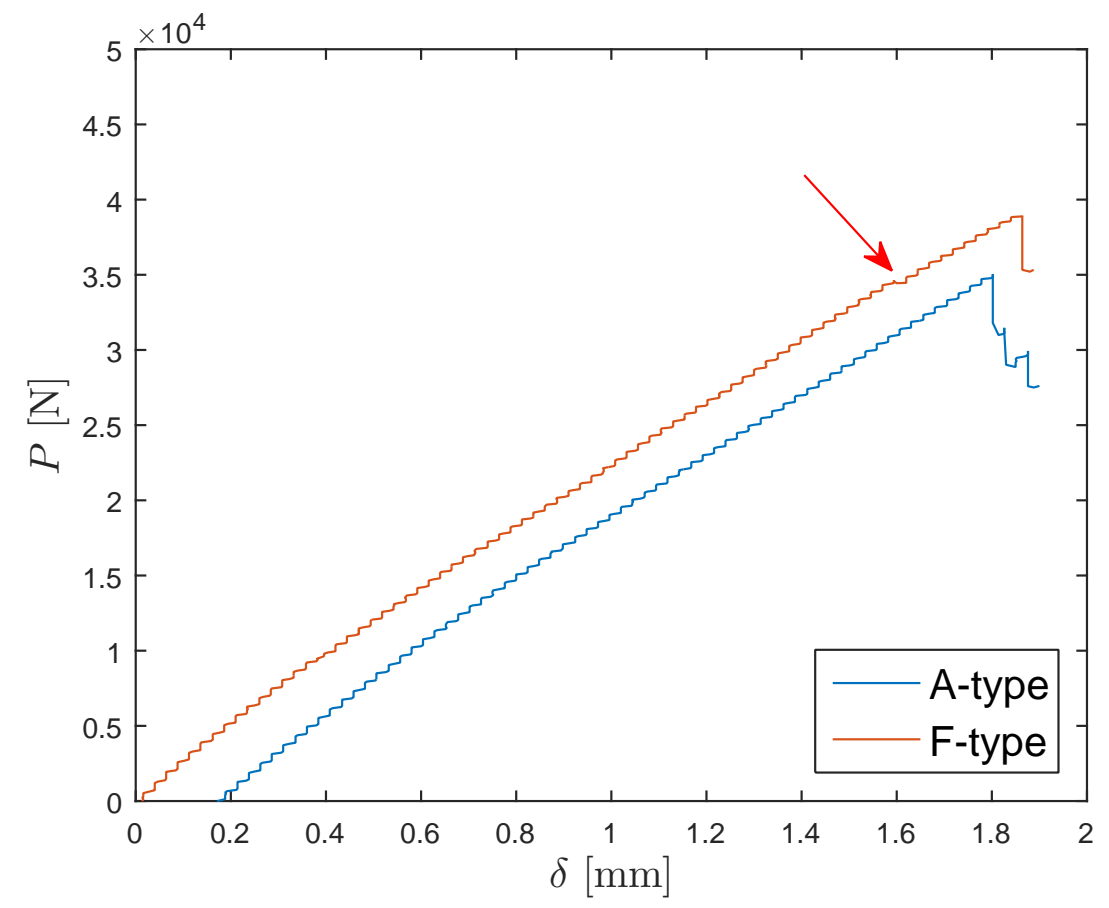

Figure 4: Typical load vs. displacement curves. 


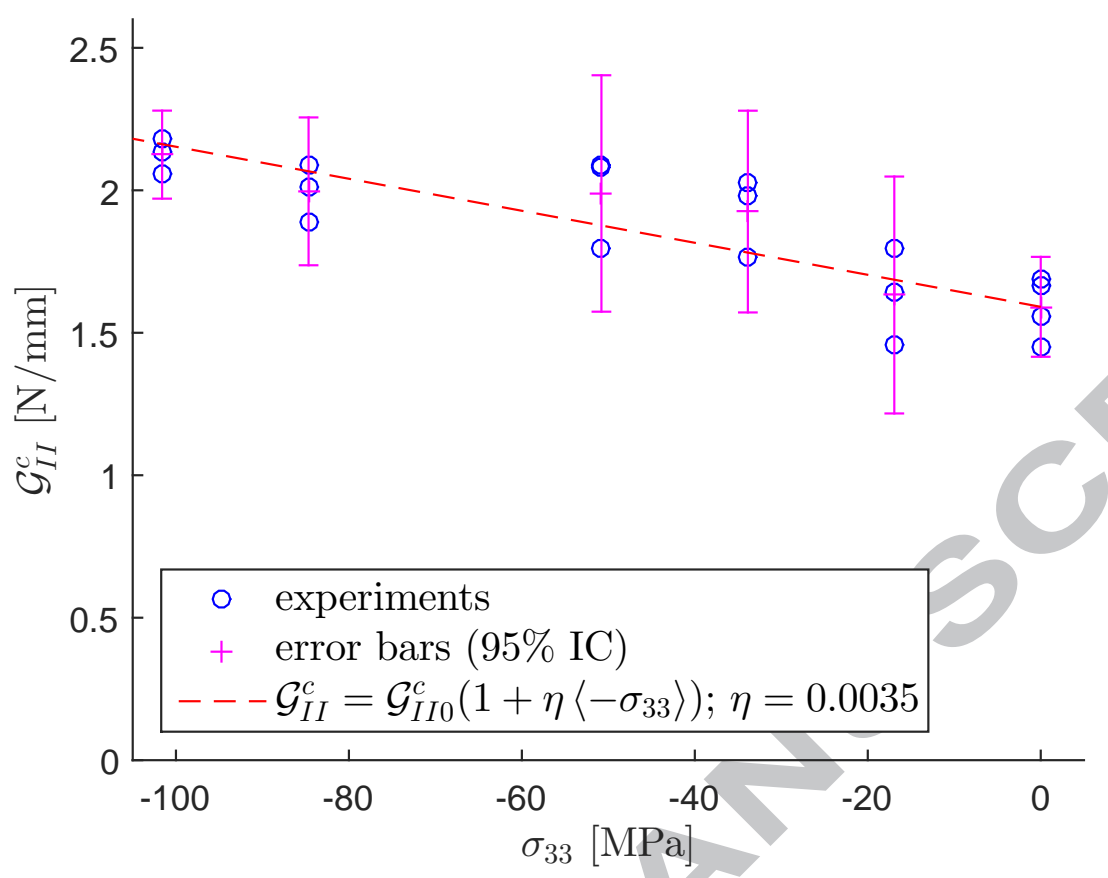

Figure 5: Mode II interlaminar fracture toughness vs. through-thickness stress.

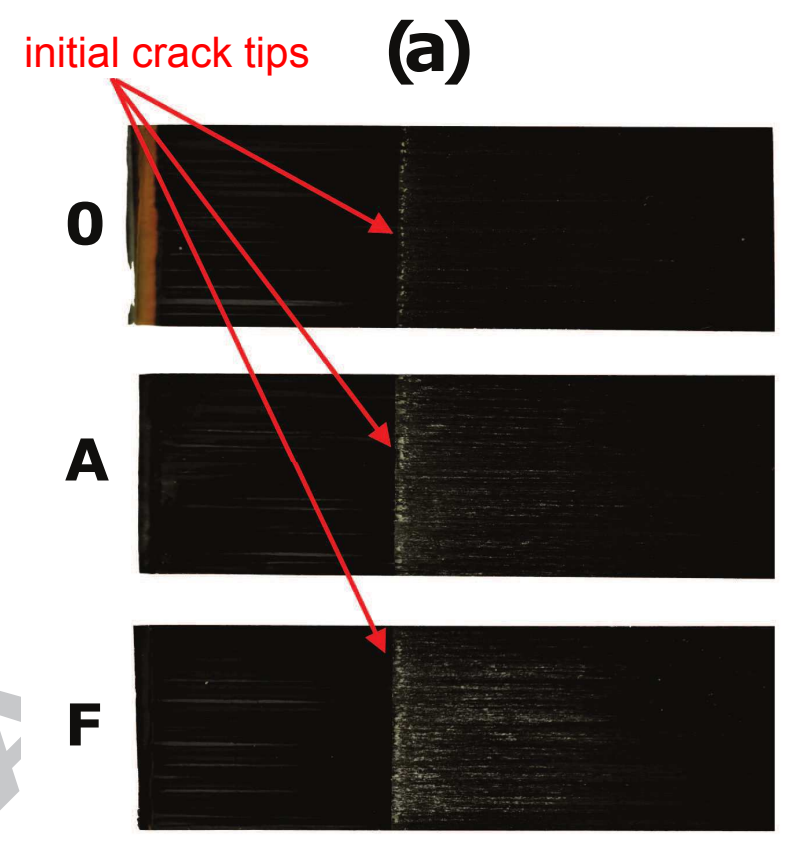

(b)
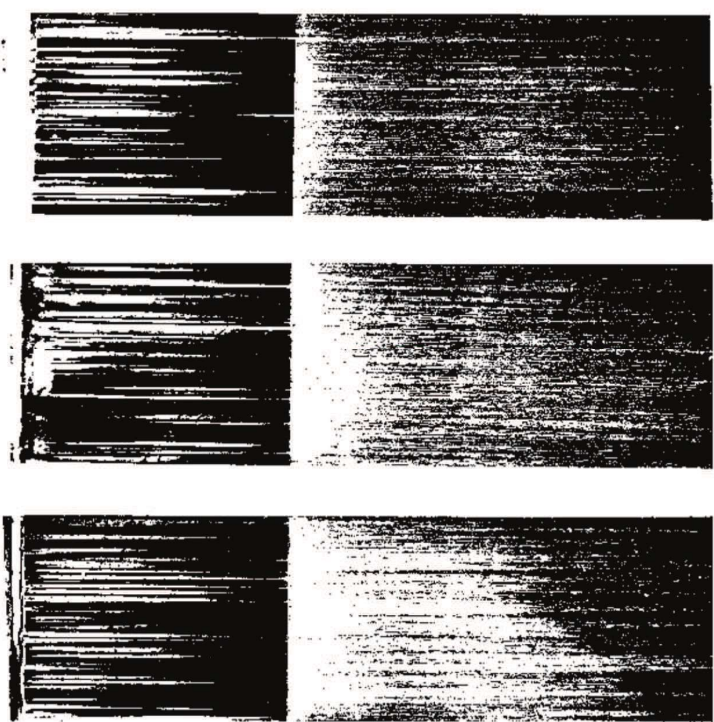

$15 \mathrm{~mm}$

Figure 6: Macro images of samples subjected to different transverse loads: (a) real image (b) binary image 


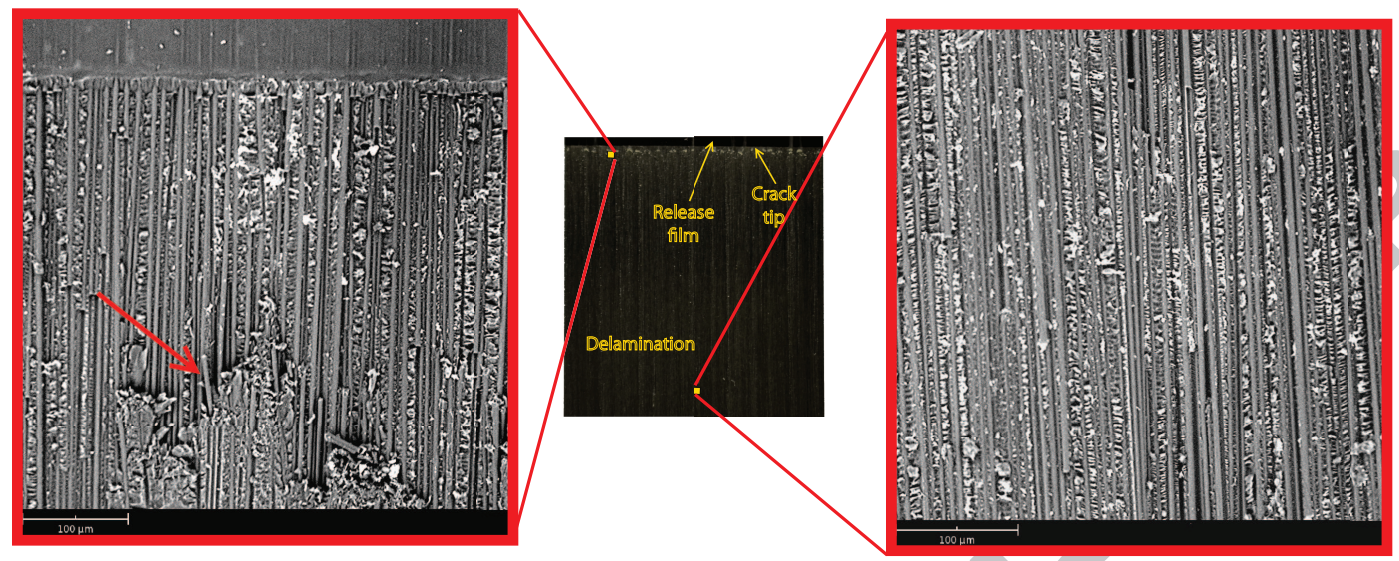

(a) Sample O.
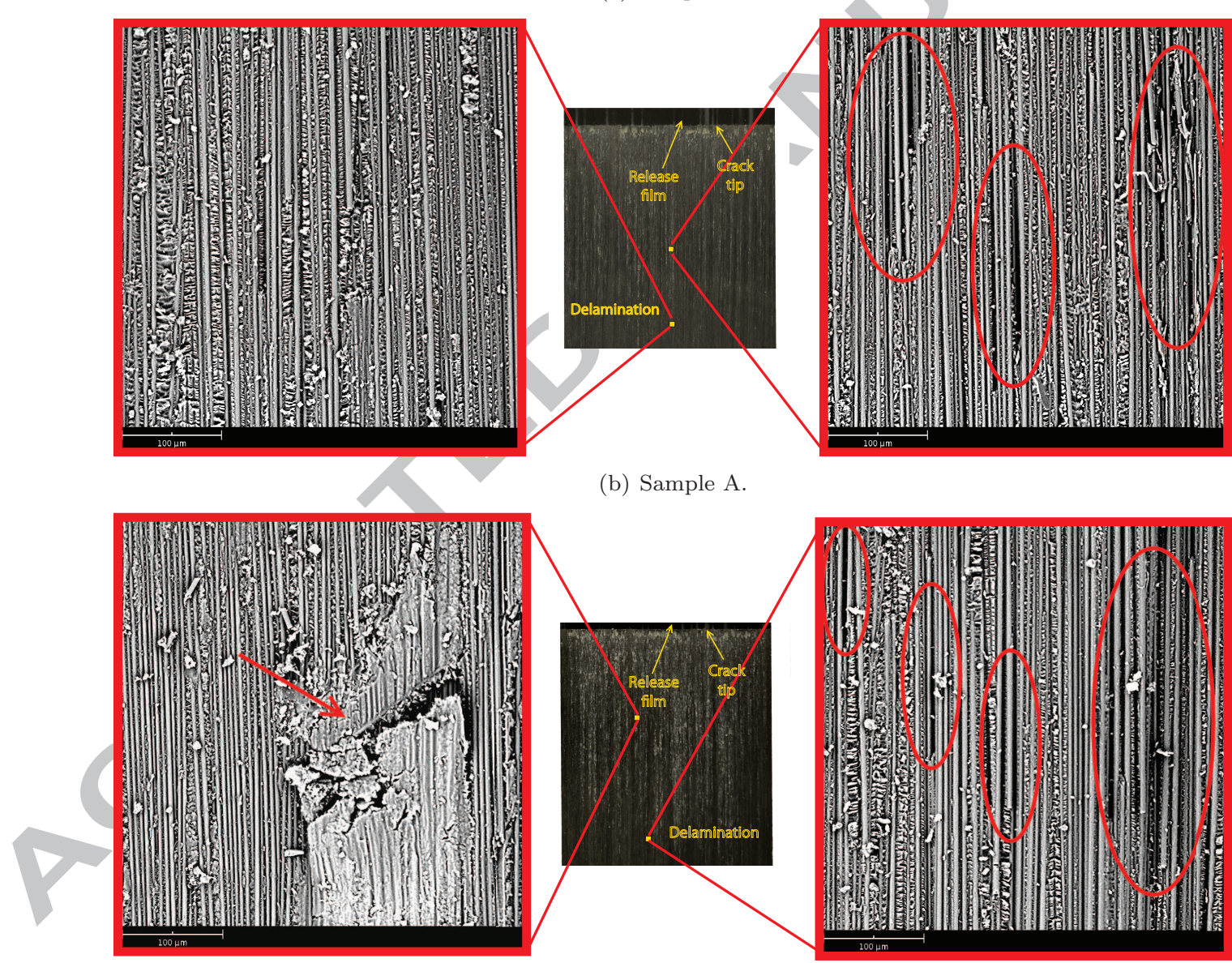

(b) Sample A

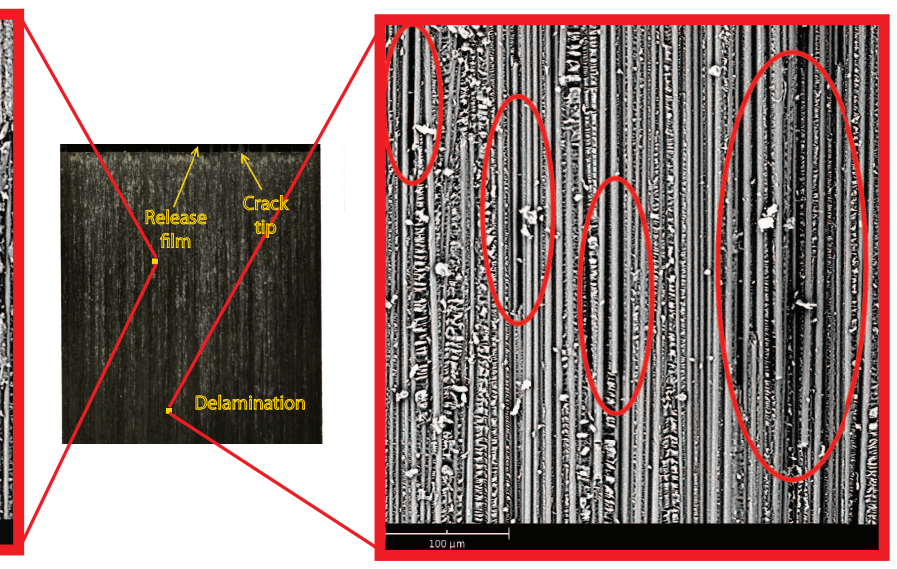

(c) Sample F.

Figure 7: SEM micrographs of the fracture surfaces for different transverse compressive stresses. 


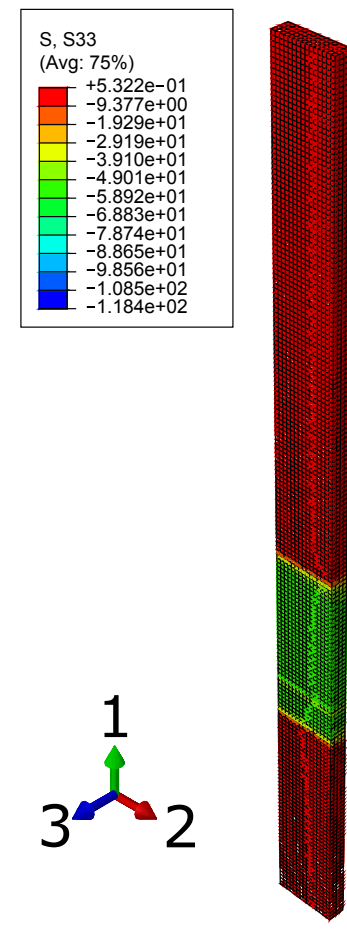

(a) before loading
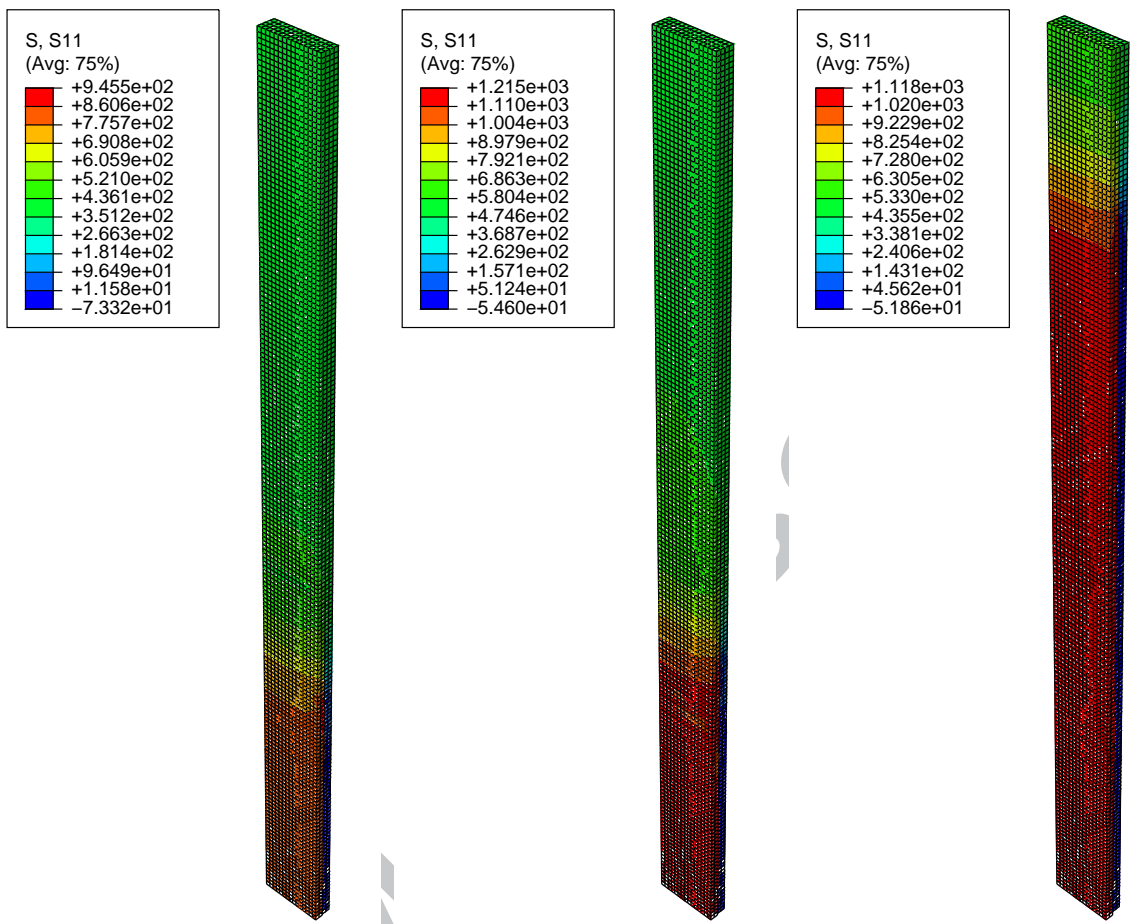

(d) At unstable crack propagation

Figure 8: Numerical results $\left(\sigma_{33}=-50 \mathrm{MPa}\right)$.

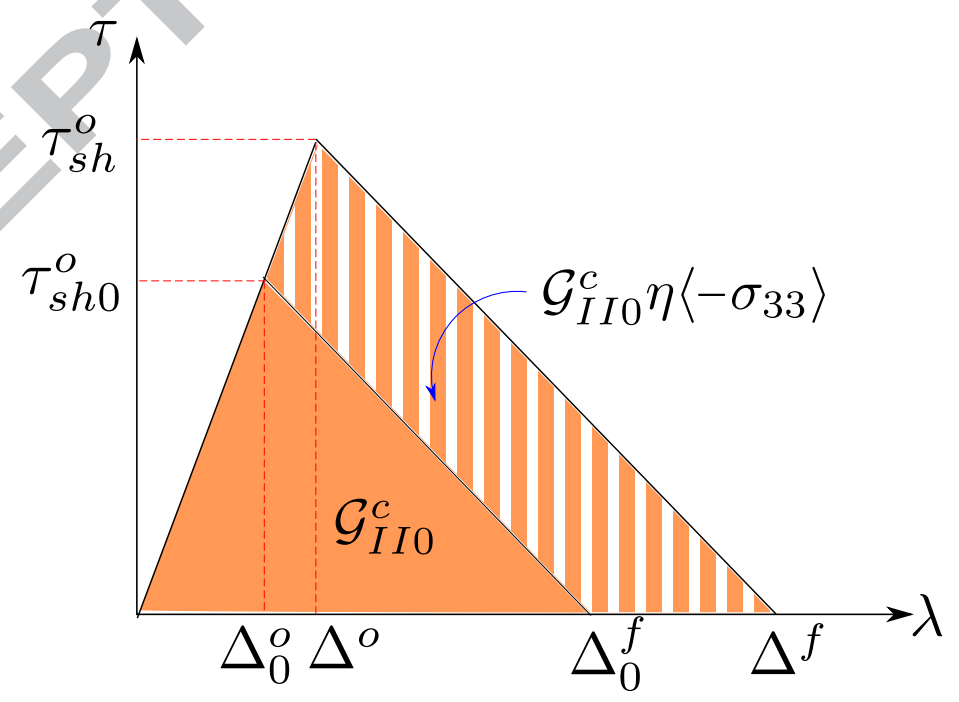

Figure 9: Mode II cohesive law under transverse compressive stress. 


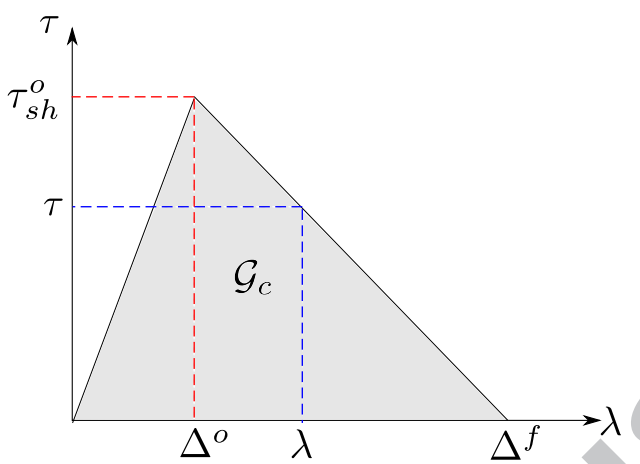

Figure 10: Parameter of the bilinear constitutive equation [50].

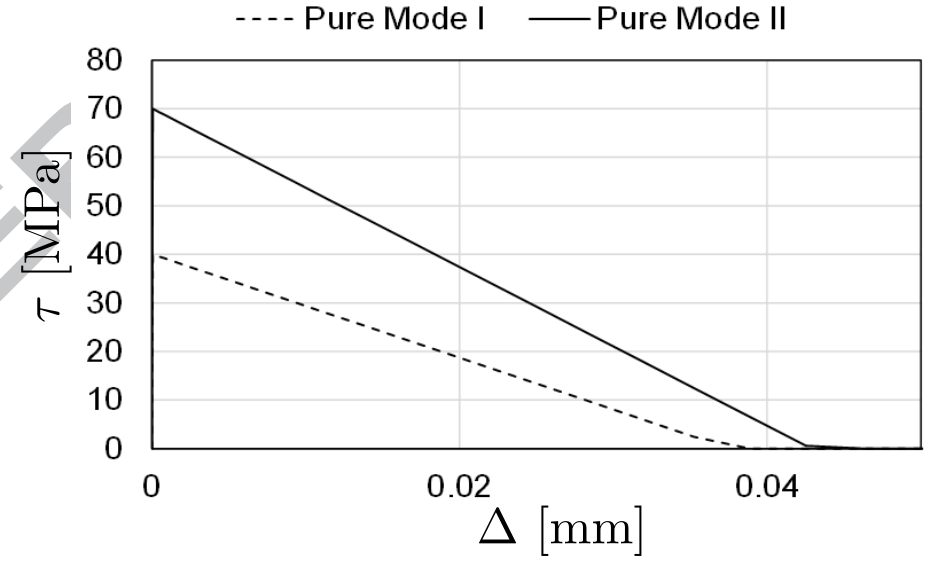

Figure 11: $\tau-\Delta$ curves for pure mode I and mode II 


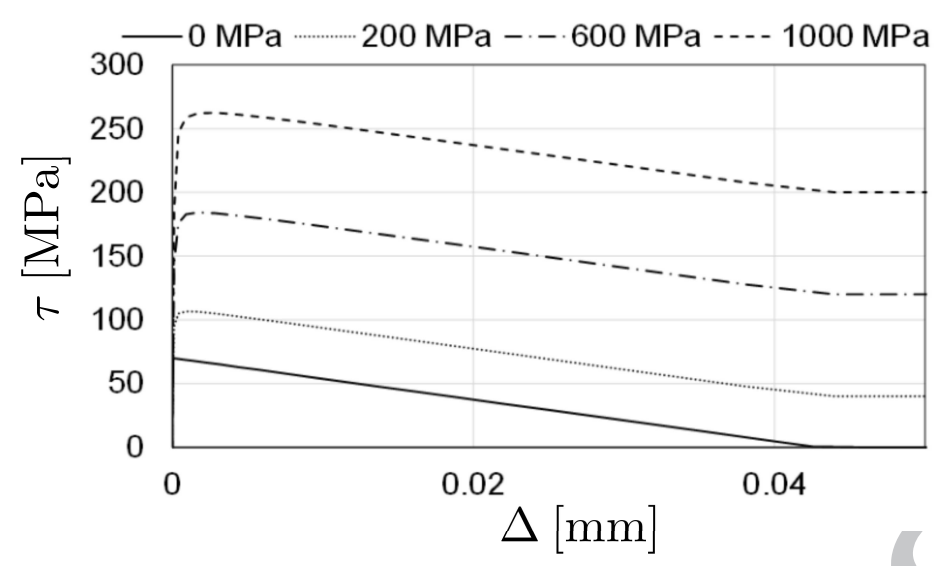

Figure 12: $\tau-\Delta$

c) The interface is subjected to constant compressive stress followed by cyclic shear loading

The traction-displacement jump curve is shown in Figure 13(a) and to support its interpretation, the evolution of damage and frictional sliding is also reported in Figure 13(b). The mechanical response during the cyclic loading is characterized by the following regions:

$\overline{A B}$ : The interface presents a linear elastic behaviour until partial damage with frictional sliding occurs;

$\overline{B C}$ : The element is unloaded with the original element stiffness and no damage propagation;

$\overline{C D}$ : Frictional sliding occurs with no damage evolution;

$\overline{D E}$ : Damage evolution restarts;

$\overline{E F}$ : The element is loaded with the original stiffness and with no damage propagation;

$\overline{F G}$ : Frictional sliding occurs with no damage evolution;

$\overline{G H}$ : Damage develops until the element is completely damaged and is only able to carry load through friction. 


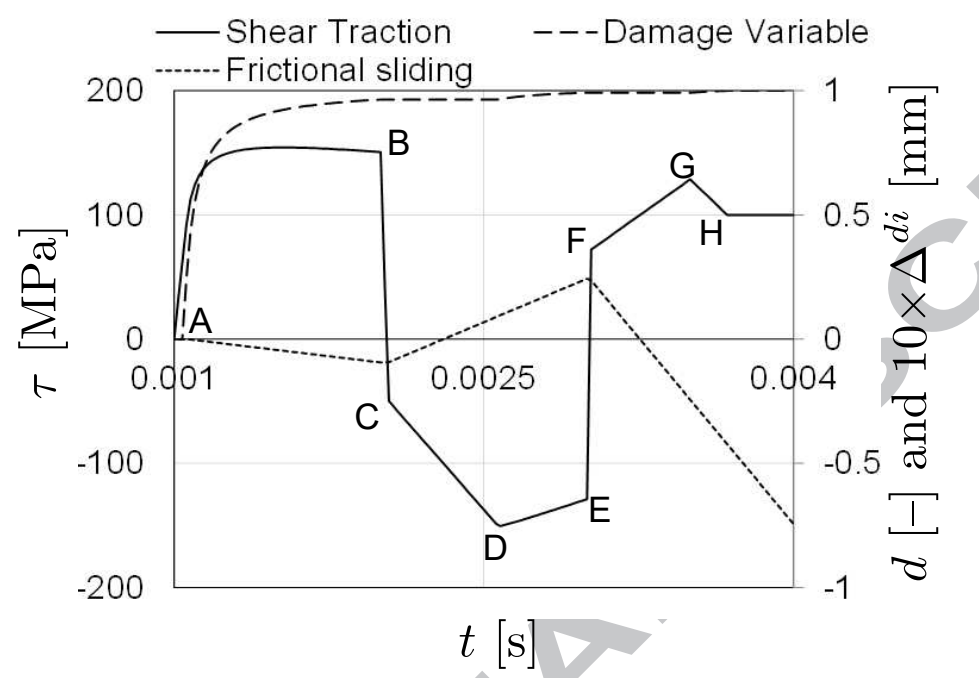

(a) $\tau_{s h}$ vs. $\Delta_{s h}$.

_Cyclic Loading with $\sigma_{33}=-500 \mathrm{MPa}$

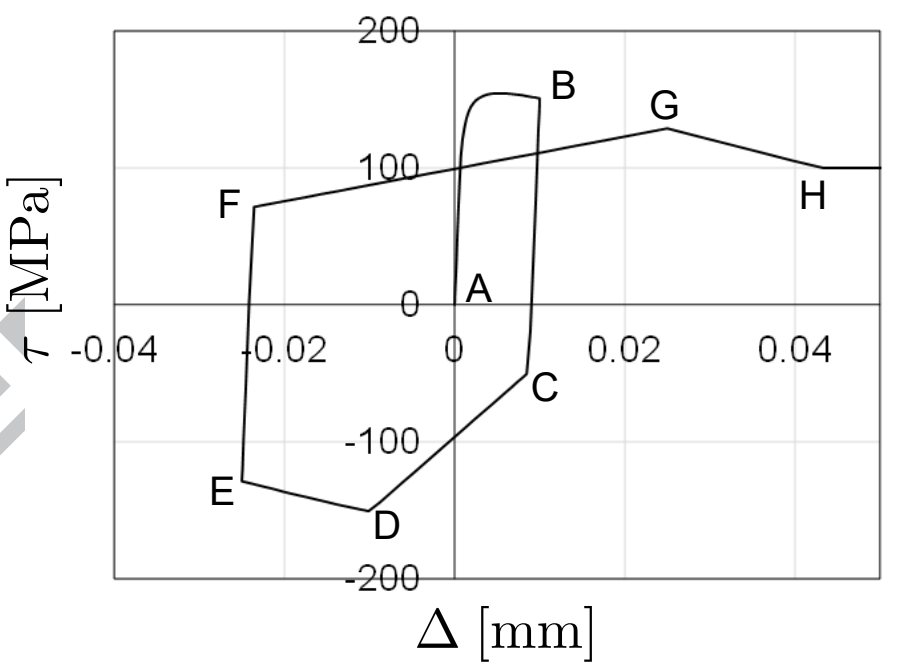

(b) Damage and sliding evolution.

Figure 13: Mechanical response of the interface during cyclic loading. 


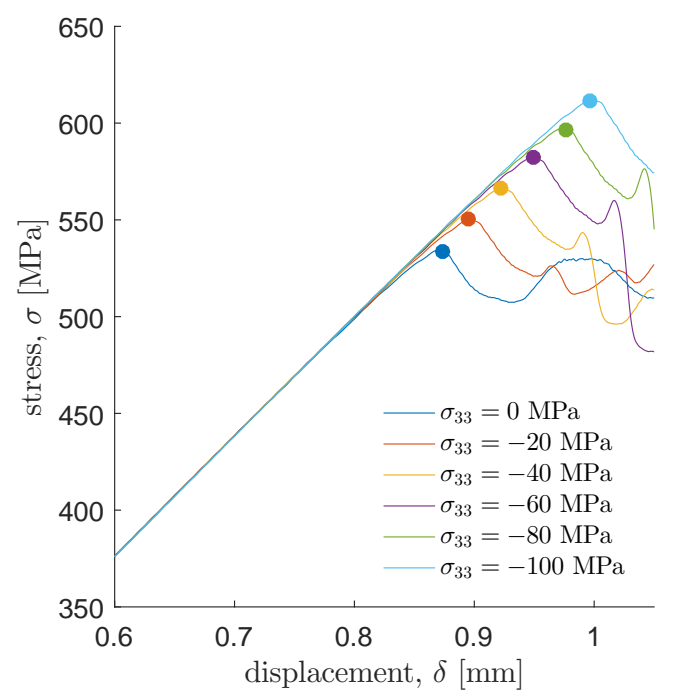

(a) VUSDFLD.

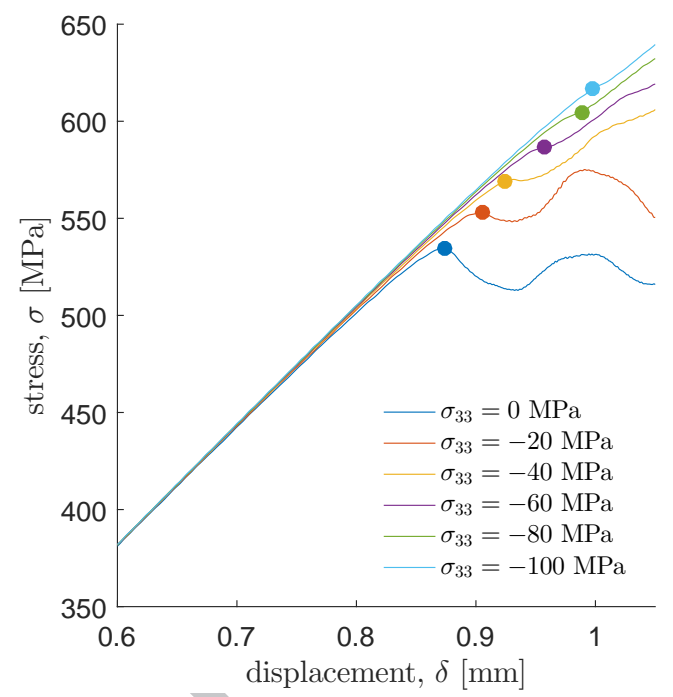

(b) VUMAT.

Figure 14: Numerical prediction of the stress vs. displacement curves obtained using a user defined field and a user material. The highlighted points indicate the loads at which the fracture process zone is completely developed.

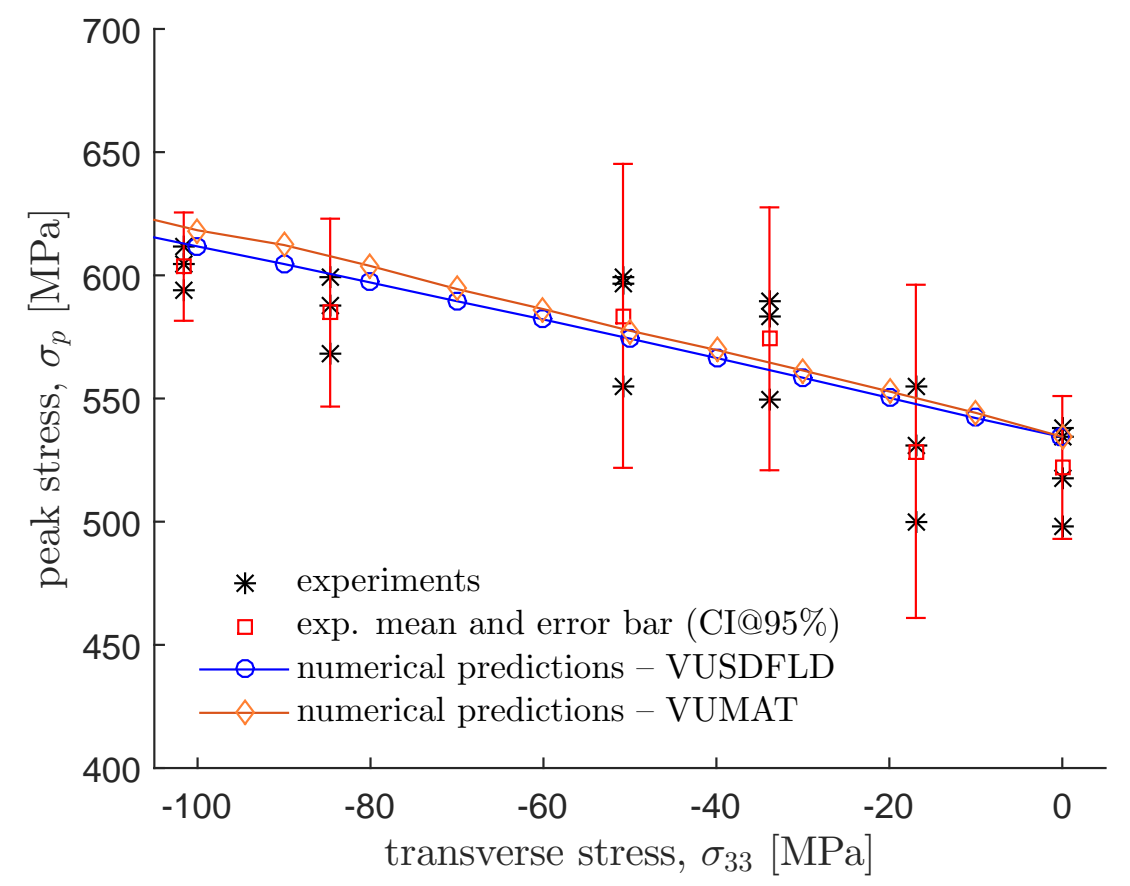

Figure 15: Numerical predictions and experiments of the peak stress vs. applied transverse stress. 